\title{
La formación del arte moderno en Colombia: planteamiento de una hipótesis de investigación
}

\section{Formation of Modern art in Colombia: Raising a Research Hypothesis}

\author{
Adryan Fabrizio Pineda \\ Universidad del Rosario, Colombia \\ faosofia@yahoo.com
}

Resumen • El artículo presenta una hipótesis de aproximación a la formación del arte moderno en Colombia que, a partir del enfoque de los conceptos de sacontecimiento` y 'mundo del artes, propone dar cuenta de la formación del arte moderno como un efecto de sentido de las interrelaciones entre el plano de las transformaciones socio-históricas y el plano de la singularidad de una producción artística impar en la historia del arte del país.

Palabras clave: Arte moderno en Colombia, Sentido, Acontecimiento, Mundo del arte, Instituciones del arte

Abstract - This paper presents a hypothesis about the formation of modern art in Colombia. Taking into account the concepts of sevent and sartworld, it proposes to account for the formation of modern art as an effect of sense in the interrelationships between the level of the socio-historical transformations and the level of the uniqueness of a remarkable artistic production in the art history of the country.

Keywords: Modern art in Colombia, Sense, Event, Artworld, Institutions of Art 
Los análisis contemporáneos del arte en Colombia parecen suscitar una cierta melancolía a raíz de una sensación de imposibilidad de dar cuenta del arte; pareciera que incluso su historia debe ser reformulada. Ante este inusual panorama, quisiera establecer una propuesta de aproximación investigativa para quien desee acercarse a estos límites. No se trata de definir los límites de lo artístico, sino de dar cuenta de cómo se llega a configurar un plano artístico en una cultura. Esta perspectiva propone entonces asumir una visión constructiva del campo artístico como fenómeno cultural, pero que reconozca las diferencias de cada caso en cuestión. No podemos seguir remitiendo a algún tipo de fenomenología de la obra de arte, sino a una perspectiva en la cual hablar del arte es dar cuenta de la consolidación del sentido del arte en un momento y lugar determinados. Así, este análisis desea poner en discusión una aproximación investigativa a la conformación del sentido del arte moderno en Colombia. Ello supone establecer las condiciones de emergencia o configuración de formación del sentido del arte moderno en Colombia, que tradicionalmente identificamos hacia mitad del siglo xx. Más que una discusión histórica sobre las peripecias de la generación de artistas de dicho periodo, deseo proponer algunas categorías de investigación que, desde un enfoque constructivista contemporáneo, den cuenta de los límites y las condiciones de formación del sentido del arte moderno en el país.

Preguntar por la formación del sentido del arte moderno invita a la pregunta por la constitución del «mundo del arte〉 (en la interpretación de Arthur Danto, que posteriormente dilucidaremos), aunque integrando un punto de vista que provea las singularidades de la composición de series problemáticas que comprenden, incluso, la posibilidad de configuración del mundo del arte en las condiciones socio-históricas del país. Por ello, «mundo del arte` puede entrar en diálogo con el concepto deleuziano de ‘acontecimiento〉 en la medida en que, en términos generales, el acontecimiento siempre requiere reconocer la estructura doble de los 〈estados de cosas〉 y del «sentido〉 que las consolida como expresión global e inmanente de los primeros. Por ello, a fin de dar cuenta de las condiciones de consolidación del arte moderno, deseo proponer diversas series problemáticas (no tanto sus respuestas) que, de manera general, interrelacionan y a veces hacen resonar entre sí algunos de los principales sucesos de la historia del arte colombiano en la primera mitad del siglo xx. Este es un periodo en el cual la plástica se transforma de diversas maneras y que pueden ser señaladas a modo de acontecimientos singulares que habrían de componer el Acontecimiento de mayor alcance: sarte moderno en Colombias. Con ello, espero mantener a lo largo de la exposición de cada serie problemática el conflicto y la comunicación entre el plano de las estructuras objetivas de los procesos del arte y el plano de la formación de sentido en la cultura colombiana de un tipo de producción artística que obtiene legitimación y realidad a través del entrecruzamiento de las distintas series y, así, propiciar un diálogo investigativo en torno a la temática, a veces olvidada, de la consolidación de un arte plenamente moderno en nuestro país.

\section{DE LA PRODUCCIÓN}

Cuando consideramos el problema de la producción artística, nos enfrentamos a la pregunta por el carácter de la misma y sus transformaciones en el país: del academicismo y la españolería a la abstracción-expresión y la investigación autónoma. Es notorio que 
durante los últimos años del siglo xix y hasta la mitad del xx, la producción artística cultivaba con aceptación social y reconocimiento oficial un naturalismo realista academizado, incansable en la repetición de paisajes, retratos y bodegones acordes al gusto de una clientela burguesa que no deseaba «adentrarse en problemas estéticos ni en laberintos intelectuales» (Gil Tovar, 326). Primaba una actitud conservadora que veía en España el refugio del país ante la «decadencia de Francia e Italia; Max Grillo registra, en 1918, la presencia de la españolería iniciada por Ricardo Gómez Campuzano, y continuada por Coriolano Leudo y Miguel Díaz Vargas (Medina, Procesos del arte en Colombia, 138). De hecho, la españolería fue asumida en el país como un principio en contra de la experimentación, más que un principio de producción propio.

En este panorama no cabía una producción artística plenamente moderna como la que estaba surgiendo en el resto del mundo. La principal tendencia que llegó a consolidarse, aunque sin una postura analítica sobre la producción, fue la llamada Escuela de la Sabana, debido a una unificación temática cuyas posibilidades de composición estaban de antemano dictadas por el tema mismo. Algo similar ocurre con las obras de Andrés de Santamaría cuyas reformas en la Escuela de Bellas Artes no fueron recibidas por los partidarios de la españolería y cuyas obras, con tintes de técnicas impresionistas, incidieron poco o nada en la producción. Sin embargo, para la década de los años treinta el carácter de la producción dio un giro hacia un reconocimiento de lo social y de las raíces americanas. La generación de los americanistas utilizó las temáticas sociales para modificar el paradigma academicista; la insignia de su producción fue una adhesión a los valores sociales, las raíces indígenas y el rechazo a las influencias europeas, lo cual se manifiesta en obras de Pedro Nel Gómez como Maternidad, y Carnaval de Carlos Correa. Estas características muestran el inicio de la transformación en la medida en que retan los valores academicistas y manifiestan la necesaria vinculación del arte con su público, tanto por medio del mural como por la representación de la cultura popular.

Esta generación ha sido objeto de varios señalamientos que, empero, desestiman su importancia. Críticos e historiadores como Francisco Gil Tovar (329) han señalado que esta producción toma unas características más literarias e ideológicas que plásticas. De manera opuesta a esta lectura, Álvaro Medina resalta la importancia de la producción artística de la generación del treinta: los temas sociales y políticos son un acontecimiento sensible, antes que uno narrativo. Para este autor, dichos temas han de ser entendidos como un signo de modernidad, a la manera como los cafés y los bulevares de París lo fueron para Monet y Rendir; rechaza así la tesis de una repetición del muralismo mexicano dando cuenta de que los temas sociales están ligados a las experiencias vitales y sensibles de los artistas — por ejemplo, barequeras, maternidades, mitos y recuerdos de la violencia para Pedro Nel Gómez- y que, más allá de la temática, se evidencia que lo principal de la obra es, en palabras de Ignacio Gómez Jaramillo, «la expresión plástica cuyo ambiente debe encaminarse hacia una interpretación de los valores humanos» (cit. en Medina, El arte colombiano de los años veinte y treinta, 309).

Las obras de estos artistas no llegaron a formular una propuesta plástica moderna como la que se encontraría en 1950 en el cuadro de Marco Ospina Aurora, pues, según Carmen María Jaramillo, estos artistas carecían del lenguaje plástico necesario para consolidar una expresión formal de este tipo; de ahí que sus obras se caracterizaran en lo formal por una austeridad ligada a un "afán de síntesis» que impidió la «explosión formal> del acontecimiento sensible que habría de aparecer a finales de los años cuarenta. La 
obra de Ospina manifiesta una particularidad que revela la transformación de la producción artística en el país: no es sólo una dirección hacia la abstracción, dado que al lado del cuadro mencionado el artista siguió elaborando cuadros figurativos, sino una actitud de negación de dependencia de la academia y de autonomía en la investigación plástica (Jaramillo, Una mirada a los orígenes, 33).

Paradójicamente, la obra de Ospina no podía desarrollar por sí misma dicho lenguaje plástico: era necesaria una influencia formada fuera de los parámetros oficiales para que el lenguaje plástico moderno pudiera ser introducido en la cultura colombiana. La influencia externa fue aportada por artistas de la generación posterior a Ospina, la gran mayoría de ellos formados fuera del país: Obregón, Grau, Negret, Ramírez Villamizar, Wiedemann. En cuanto a su producción, traían el lenguaje que habían recibido al entrar en contacto con el mundo del arte de Europa y Norteamérica y sus obras no fueron concebidas bajo criterio alguno de oposición: ni temática, como los americanistas, pues sus obras manifiestan una sensibilidad a las circunstancias y características regionales del país, ni generacional, pues esta producción artística refleja un interés investigativo estrictamente estético. Nace así una producción sensible a lenguajes plásticos modernos en Colombia, la cual recoge la transformación de la generación del 30 en cuanto a la ruptura con el academicismo y el valor de los contenidos contextuales, adoptándolos en un lenguaje plástico preocupado esencialmente por la concreción formal y conceptual de la producción artística. Obras apolíticas y trabajos independientes se abrieron paso entre las instituciones de arte hasta alcanzar, una vez apropiados los signos contextuales y la expresión liberada, una representación en el circuito internacional. Barney-Cabrera lamenta que esta generación tratara temas abstractos, alejados de las circunstancias sociales y políticas del país catalogándolos de obras «extrahumanas y extraterritoriales» (Barney-Cabrera, 210), pero la obra de arte moderna requirió precisamente, como primera condición, anular de la producción raíces politizadas en la cultura, recibiendo material plástico internacional, para sintetizarlo en una producción sensible original. No ocurre una inclemencia frente al contexto; por el contrario, Paisaje (1942) de Wiedemann da cuenta de una nueva sensibilidad plástica presentada al ojo del público, un acontecimiento sensible que supone y atraviesa un nuevo aparato conceptual, una reforma de los espacios de socialización del arte y una expansión de la noción misma del arte en la cultura colombiana.

Apéndice 1: Deseo aclarar brevemente la tesis del mundo del arte. Ésta puede ser leída como la tesis de la adquisición de un carácter ontológico en la producción artística por medio de la modificación de la teoría o concepción prevaleciente del arte. Esta transformación es identificada por Arthur Danto en el advenimiento del post-impresionismo. La teoría artística atacada por las vanguardias de inicios de siglo xx, la Teoría de la Imitación, sólo aceptaba estas tendencias como un arte inepto. Lo que se requirió para ser aceptada como arte fue una revisión teorética sobre los rasgos definitorios de lo que se entiende por obra de arte, a fin de proporcionar nuevos parámetros de definición. Tal fue lo que ocurrió con los post-impresionistas al no identificarlos ya como errores de imitación de formas reales, sino como creación de nuevas formas, reales en sí mismas. Así, la aceptación de esta nueva teoría conlleva un nuevo modo de ver la vieja y la nueva pintura como objetos reales en sí mismos y con el mismo estatuto artístico. La nueva manera de identificar el arte es posible por una atmósfera en la que toman parte la teoría artística vigente y la historia del arte actual y remota. Esta atmósfera de teoría artística 
y conocimiento de historia del arte es algo que el ojo no puede percibir; es lo que Danto denomina «mundo del arte» (Danto, 571-584). Aunque un cuadro no es más que una cosa, la teoría del arte es lo que le otorga «ciudadanía» en el mundo del arte, lo introduce en la narración de la historia del arte; lo que supone que si la teoría no está todavía consolidada, dicho cuadro no será arte.

\section{DE LA RECEPCIÓN}

Otra perspectiva problemática sobre el acontecimiento arte moderno en Colombia tiene que ver con la aptitud de la cultura del país para su recepción. Esta se compone de elementos que vinculan tanto modelos ideológicos como prácticas institucionalizadas. Esta duplicidad se manifiesta en el hecho de que no sólo el arte moderno emergió tarde en Colombia respecto a otros países de Latinoamérica; también el modelo ideológico o el marco valorativo de la sociedad era, principalmente, conservador en términos culturales. Esta mentalidad conservadora se acomoda también al dominio católico que, en conjunto, dilataron intentos sucesivos de modernización en los distintos ámbitos de la sociedad colombiana. A esto se suma la tendencia cultural a ver en los partidos fuentes de identificación social, a lo cual no fue ajeno el arte — tal como lo evidencian las constantes críticas al expresionismo por parte de Laureano Gómez (Lleras, 79)—. Los circuitos del arte, hasta mediados del siglo $\mathrm{xx}$, estaban circundados por instancias políticas y religiosas. Pero ni siquiera la introducción del capitalismo y la apertura al exterior, que inició de la modernización del 'país político', modificó el conservatismo en cultura y artes: la misma mentalidad católico-conservadora se manifiesta en el II Salón Nacional en contra de la obra Anunciación de Carlos Correa, por orden del arzobispado, y en el VIII Salón con la premiación, y el simultáneo silencio de la crítica de arte, del busto de Laureano Gómez hecho por Moisés Vargas (Lleras, 66).

No fue sino hasta el fin de la hegemonía del partido conservador que la modernización de las estructuras sociales y económicas caminó junto a la modernización de los modelos culturales aceptando un campo autónomo para las instituciones del arte. Sin embargo, este proceso no se hizo posible por una reforma al interior de las instituciones oficiales; éstas habían reproducido una valoración utilitaria del arte, afirmando la idea de una responsabilidad de la obra y del artista con la sociedad, esto es, que debía cumplir una misión educativa, al servicio del Estado, que elevara al pueblo de su estado de ignorancia e incultura (Lleras, 104). Frente a este panorama, la estrategia fue casi desesperada, y a la vez subversiva: la situación de emergencia en el orden público entre 1946 y 1957 desvió la mirada de los gobiernos conservadores de los aspectos culturales, dando cabida a prácticas privadas e iniciativas individuales que pusieron en diálogo el arte internacional con la nueva generación de los años cincuenta. Así, el carácter apolítico que lamenta BarneyCabrera tiene humana explicación como fatiga de todo compromiso sectario y como un interés en la pintura como tal, individualista, pero diversa y enfocada. Aquí, entonces, el arte moderno aparece como un acontecimiento social que sobrepasa las restricciones de la tradición ideológica para presentar una producción moderna enfocada en su quehacer y, por ello, propicia para la revolución cultural del ‘país real. 


\section{DEL ESPACIO}

Hasta el momento, he recogido dos categorías tradicionales de los estudios sobre el arte, ligando ambos a la especificidad de su contexto, o si se quiere territorio. Pero la consolidación de un sentido también puede responder al problema del espacio, o mejor dicho, a la espacialización del mismo. Esto es algo que la historiografía del arte en Colombia, como toda narración histórica, tiende a abstraer al generar un efecto de totalidad y agrupamiento de la producción que resulta útil en el análisis, pero abstracto frente a la espacialidad del estado de cosas. De hecho, aunque aquí hemos hecho alusión a distintas generaciones, este término no puede ser tomado sino como un instrumento analítico; la producción artística en el país no sólo ha carecido de escuelas artísticas sino de generaciones, en el sentido en que ambas nociones suponen un trabajo o voluntad común entre sus miembros. Sin embargo, sí hubo una congruencia entre las distintas producciones individuales. Esto no por razón de un común acuerdo, sino por un efecto de espacialización de la producción. Hay una espacialización singular en arte moderno que se hace problemática en los diversos recorridos del arte nacional.

Este tópico del espacio del arte fue señalado con detenimiento por el crítico BarneyCabrera, para quien el arte moderno hizo el tránsito de una insularidad, pasando por un centro de congruencia, a la extraterritorialidad. Insularidad no remite a individualidad; por el contrario, parece suponer una visión común a un número determinado de personas que, empero, no influyen, o lo hacen mínimamente, en otras regiones del país. La insularidad es ajena a la investigación artística alimentada por la voluntad compartida - a la manera de los impresionistas, cubistas o fauvistas-, es, en palabras de este crítico, «un fenómeno de resistencia y falso orgullo que aísla en busca de la facilidad, del impulso brillante que permite la improvisación y separa del análisis y de la investigación» (11). El aislamiento era legitimado en virtud de las escasas, pero prestigiosas, instituciones de arte de la época, como la Escuela de Artes Plásticas de Popayán, en la cual Emilio Porcet y Coriolano Leudo fueron directores ceñidos a un academicismo filohispanista y un sentimentalismo histórico y paisajista que tuvo gran influencia, no sólo en el alumnado, sino en la complaciente satisfacción estética de la aristocracia por ellos retratada.

La respuesta a la insularidad fue la centralización de los procesos de modernización del país en la capital. El fenómeno de centralización en las artes se manifestó en dos pasos. En primer lugar, la región de Antioquia hizo notar en el arte nacional una diferencia en sus dinámicas de manera doble: si, por una parte, en esta región los contemporáneos de Pedro Nel Gómez fueron lectores atentos de la historia de su tiempo y de las transformaciones ocurridas en las artes extranjeras, por otra parte, sus obras de arte eran concebidas bajo el principio de alejamiento de las temáticas clásicas europeas y de auto-afirmación de lo propio (Rubiano, Pintores y escultores «Bachués`). Así, el espacio de este inicio de modernidad nace tanto de un reconocimiento del territorio como de un cerramiento crítico ante las condiciones heredadas en el país. Esto se vio a su vez apoyado por el segundo paso: la institucionalización de un espacio de presentación y crítica de la producción artística anual en todo el territorio nacional, a saber, el Salón Anual de Artistas Colombianos. El I Salón fue convocado en 1940 con el objetivo de «favorecer una conciencia gremial» entre los artistas, en el cual participaron los artistas antioqueños 
obteniendo los primeros premios. La institucionalización del salón nacional generó un efecto de centralización de los procesos del arte que serviría de dispositivo de visualización de la producción y confrontación de propuestas.

La consolidación de un espacio propio de la plástica moderna vendría a aparecer en el transcurso del primer al décimo salón nacional. El espacio de esta nueva producción es, para usar un término aludido, extraterritorial: el arte moderno, aunque recoge elementos iconográficos del entorno y fortalece el interés de una producción propia, es impulsado prioritariamente por corrientes foráneas que hacen tambalear la tranquila estructura institucional académica. Artistas como Alejandro Obregón y Enrique Grau no sólo se desinteresaron de cualquier compromiso social en el arte, convirtiendo los temas territoriales en motivos de investigación plástica; su producción también inició el cambio del gusto de clase por la experiencia sensible de la plástica en la generación en formación que los observaba. El trabajo de estos artistas tuvo una pronta repercusión en el circuito internacional, no sólo por las fortalezas de sus trabajos individuales sino porque sus obras manejaban el lenguaje y teorías del mundo del arte extra-nacional; lo particular de esta incorporación es que la recepción de un artista como Wiedemann fue posible gracias a la visibilidad del arte fomentada por las nacientes instituciones de exposición paralelas al salón nacional, particularmente galerías de arte, así como por la renovación y profesionalización fundamental de la crítica de arte por parte de una constelación de críticos extranjeros. Es así, que el problema espacial del arte moderno en Colombia requirió de una ruptura en la insularidad fomentada por las élites académicas mediante la centralización temática e institucional de los procesos del arte; pero, además, necesitaba la apropiación de los lenguajes foráneos para la síntesis de propuestas novedosas que, apoyada por una crítica conocedora de dichos lenguajes, excedió para finales de los años cincuenta cualquier sentido o compromiso con el territorio al devenir un producto internacional.

Apéndice 2: ¿Qué significa ‘Acontecimiento`? El Acontecimiento para Gilles Deleuze es una estructura compleja que se compone de una dimensión doble: la multiplicidad de las relaciones que conforman los estados de cosas y los efectos incorporales causados por los primeros pero desarrollados como singularidades de manera independiente. Los estados de cosas se componen de mezclas de cuerpos y son expresados por una proposición. Los efectos incorporales son singularidades que caracterizan de manera ideal a los estados de cosas. Por ello, el Acontecimiento se realiza en una superficie en la cual las singularidades componen series dando lugar a otras subseries. Así, en la relación entre la serie ideal de los acontecimientos y la serie real de los estados de cosas de los que son efectos, las series resuenan y las singularidades se redistribuyen. De ahí que lo óntico del Acontecimiento es que éste se distingue de su efectuación espacio-temporal en un estado de cosas. El Acontecimiento es efecto en la superficie en donde configura el sentido que lo hace independiente de cualquier cosa a la que pueda ser atribuido y, a la vez, inmanente a la multiplicidad inabarcable de las dinámicas propias de los cuerpos que exceden por sí mismos la capacidad de ordenarlos o dirigirlos (Deleuze, 73). De esta manera, las condiciones para un Acontecimiento son: 1) la efectuación y convergencia (o divergencia) de series heterogéneas en un sistema con una potencia genética de sentido que distribuye las diferencias entre ellas (serialización); 2) un proceso de autounificación signado por un elemento paradójico, singular, que está presente y comunica las series entre sí (univocidad); 3) la emergencia de una superficie de contacto entre los efectos de sentido y los estados de cosas vinculados por una relación de expresión (lenguaje); 4) la impasibilidad 
como lugar del sentido en el cual los signos entran en una serie que se diferencia de sus actualizaciones y asegura la continuidad (campo impersonal y preindividual). La manera en que estas descripciones se entrecruzan es en el problema: lo que hace problema, allí donde y cuando ocurre, hace Acontecimiento; el sentido tiene por estatuto lo problemático.

\section{DE LAS INSTITUCIONES}

La idea de un arte moderno en Colombia también tiene otra problematización que deriva de la anterior: aun si el espacio de realización de una propuesta estética autónoma es el de una extraterritorialidad, esa propuesta requiere un mundo de sedimentación que comporte líneas de territorialización, en otras palabras, un mundo institucional que configure la estructura de relaciones legitimadas socialmente en las prácticas artísticas. Este es un problema central para el arte moderno, pues antes de la década del 40 las instituciones de arte eran escasas y estaban ceñidas a los paradigmas clásicos. El panorama de las instituciones entre 1920 y 1940 es apenas precario: los salones de exposiciones, así como las galerías de arte no eran especializadas y exhibían sin criterio obras de distintos tipos; en 1920 se funda el Círculo de Bellas Artes, quien manifiesta un carácter recalcitrante ante las innovaciones; finalmente, una institución museal dedicada al arte moderno en el país no surgió sino hasta la ampliación del Museo Nacional en el antiguo panóptico en 1948. Las estructuras objetivas del acontecimiento arte moderno en Colombia no estaban en condiciones óptimas para su realización antes de 1940.

La institucionalización del Salón Anual de Artistas Colombianos fue parte de una reestructuración de la Sección Cultural y de Bellas Artes del Ministerio de Educación, culminada por el entonces ministro Jorge Eliecer Gaitán en 1940 (Rubiano, Museos, Salones, Bienales, Escuelas, 1426); antes de esta fecha se realizaron exposiciones nacionales patrocinadas por el Estado, pero, según Beatriz González, «es a partir de 1940 cuando se observa una voluntad gubernamental clara de estructurar una competencia anual de tipo artístico» (27). Sin embargo, los miembros de las clases dirigentes no pudieron evitar hacer notar su displicencia frente a las propuestas más incisivas de los artistas, como lo evidencia el escándalo desencadenado por La anunciación de Carlos Correa (González, 28). Ciertamente, ello propició fuertes comentarios de políticos conservadores tanto frente a las obras y los artistas como hacia el gobierno liberal que patrocinaba estos casos de inmoralidad, pero los liberales tampoco hicieron esfuerzos por defender a estos artistas. Así, se puede identificar, en la concepción misma de la institución, una raigambre conservadora que se reprodujo con vigor en los gobiernos de Ospina y Gómez, en los cuales los Salones realizados revelaron sectarismo y sumisión del arte a las figuras del poder.

Sin embargo, el problema de la institucionalidad no debe ser reducido a estos términos. A partir del I Salón, esta institución del arte se convertiría en el lugar de encuentro y discusión de una crítica profesional alimentada por las capacidades individuales de críticos extranjeros. Además, hay que reconocer el proceso interno de apertura de la institución: en el reglamento estipulado para el I Salón sólo se contemplaban pinturas y esculturas y sólo aquellas que utilizaban técnicas tradicionales; en 1946 se amplían las características para fomentar obras clásicas; ya para 1957 se admiten toda clase de técnicas o procedimientos y la mayoría de obras son de tipo abstracto o expresionista. Esto 
hay que reconocerlo junto a los cambios en la selección de los jurados: inicialmente eran poetas o diplomáticos sin formación en el tema y con un sentido de complicidad; sólo en el X Salón se instituye que los jurados deben ser historiadores o críticos de arte, lo cual renovó el ánimo de los artistas participantes, pues la selección de poetas o diplomáticos generó una sensación de control sobre el arte y de rechazo por parte de los artistas, que se manifestó cuando se realizó el IV Salón en Medellín y en el cual los artistas antioqueños no sólo se negaron a participar sino que simultáneamente organizaron, liderados por Pedro Nel Gómez, el Salón de los Independientes, con una participación de más de 150 obras (evento que tuvo su contrapartida en 1946 cuando los maestros académicos organizaron el Salón de los Rechazados). Las múltiples relaciones entre reglamentos, jurados, críticos y participantes hizo notorio el contraste entre obras centenaristas y obras que se adentraban en la modernidad plástica, lo cual indica la ruptura en la producción y el inicio de un proceso de adquisición de autonomía en las instituciones del arte que culminará en el X Salón con la apertura a obras con un lenguaje plástico independiente y propositivo en términos netamente estéticos.

La relevancia aquí presentada al Salón Nacional no es suficiente para dar cuenta del problema institucional que atravesó la modernización del arte colombiano. El fenómeno del Salón de los Independientes es un signo de lo que pasaría en adelante. En tanto el rechazo de los artistas no era sólo a la centralización del control del arte sino también a la dominación ideológica que le subyacía (Medina, 287; Jaramillo, Una mirada a los orígenes, 30$)$, los artistas jóvenes asumieron como actitud productiva la marginación de la institucionalidad oficial trabajando en la sombra o emigrando a Europa o Estados Unidos, cuyo efecto fue la apertura a los lenguajes plásticos modernos y la aparición de instituciones privadas de arte, a saber, las galerías de arte. Aunque hubo algunas exposiciones colectivas patrocinadas por una institución oficial en la que participaron los jóvenes artistas, fueron algunos críticos de arte quienes organizaron y fomentaron este fenómeno que podríamos llamar para-institucional, cuyo resultado fue la institucionalización de nuevos medios de circulación del arte y de validación de un lenguaje plástico alterno al apoyado por la institución oficial (Jaramillo, Una aproximación a la consolidación, 25). Este fenómeno de para-institucionalidad puede identificarse en las crónicas de Casimiro Eiger, quien resalta la importancia de las Galerías de Arte como sitio de encuentro de «valores plásticos» extranjeros y nacionales y de creadores y espectadores, al exponer obras contemporáneas de Picasso, Chirico y Dalí a la vez que de todo el conjunto de jóvenes artistas innovadores (Eiger, 139).

Las dinámicas anteriores muestran que fue necesario que se institucionalizaran estos mecanismos marginales para el establecimiento y aceptación de propuestas artísticas que rechazaban los parámetros tradicionales, escapaban a una intervención oficial, sintetizaban propuestas plásticas conscientes y auténticas, portando elementos de ruptura de las fronteras nacionales que fueron reconocidos y fomentados por una crítica profesional. Dinámicas que se fortalecieron con los programas radiales de Casimiro Eiger y posteriormente los televisivos de Marta Traba; pero también con el espacio generado por la artista abstracta Judith Márquez al fundar la Revista Plástica, primera publicación especializada en arte no figurativo: aquí se ponían en discusión eventos internacionales del mundo del arte, la producción moderna latinoamericana, textos e ideas de críticos e historiadores del momento y una evaluación profesional de la novedad en el arte colombiano (Rubiano, El primer arte abstracto en Colombia, 1402). Este ánimo crítico centrado en 
la obra de arte emergente dio frutos en la reactivación del Salón Nacional, en el cual se legitimó la producción artística moderna en el país. A partir de este momento los jóvenes artistas se consagrarían como artistas modernos con propuestas propias y proyección internacional. Así, el sentido de la emergencia de un arte moderno en Colombia está intrínsecamente vinculado con la consolidación de una compleja red de fenómenos institucionales que consagraron una producción autónoma y plásticamente novedosa en la cual la obra deviene el producto pleno de sentido, esto es, singular en sus características y universalizable en el mundo del arte — un verdadero acontecimiento.

\section{DEL TIEMPO}

Cada ámbito problemático señalado hasta el momento ha dado cuenta de diversas transformaciones en la plástica colombiana, lo cual ha supuesto la reunión de factores ligados a la producción, la cultura, el espacio y las instituciones del arte. Éstos han mostrado devenires distintos entre sí. Sin embargo, algo que atraviesa a cada uno, pero es, a la vez, independiente, es la variable temporal de la consolidación del acontecimiento. Cada serie problemática asume una temporalidad propia, pero el acontecimiento general que aquí nos cuestiona, el sentido del arte moderno en Colombia, manifiesta una temporalidad propia que puede ser puesta en relieve en sí misma. De hecho, el arte moderno en Colombia puede ser visto como producto de una aceleración en la multiplicidad de sus relaciones.

Entre 1894 y 1934 el arte colombiano permaneció en un estado de inercia, un movimiento constante que se manifiesta en el predominio, en la producción y la recepción cultural, de una interpretación costumbrista del arte. La producción se acomoda a los gustos de clase y ésta perfila los límites claros de acción del artista circunscrito a la insularidad de una academia sin crítica. No había afán de problematización de principios; la obra se agotaba en el método. Puede evidenciarse esta inercia comparando con otros países de América Latina, por ejemplo, Brasil, donde se realizó en 1922 la Semana de Arte moderno (Escallón, 208). También resulta notorio en la preponderancia del letargo costumbrista colombiano al considerar el caso de Santamaría: si bien es cierto que parte de sus estudiantes se apropiaron de sus técnicas, estos mismos artistas terminaron por replantear la influencia de su maestro en equilibrio con los métodos tradicionales de la representación (Quinche). Así, la inercia de las actividades artísticas en este periodo estaba signada por el academicismo filohispanista afianzado y fomentado por el gusto de clase.

Para que haya velocidad debe haber cambio de dirección, la aplicación de una fuerza que quiebre el rumbo dictado por la inercia. En el arte colombiano, el quiebre se inició en la década del treinta. Las obras de arte de la generación americanista o «Bachué modificaron las dinámicas del arte como un acto de incursión en la modernidad. Así lo rubrica el crítico Walter Engel quien encuentra en las exposiciones de Ignacio Gómez Jaramillo en el Teatro Colón y la exhibición de cien cuadros de Pedro Nel Gómez en el Salón Central del Capitolio Nacional, en 1934, un inicio de independencia. Esta producción, en medio de esfuerzos discontinuos y un ambiente cultural politizado, halló en un periodo de diez años el camino de su consagración artística, sellada con su participación en el I Salón donde se legitimó la relevancia de estos artistas y se evidenció la ruptura con el arte finisecular. El último golpe por parte de esta generación, que abre el camino hacia 
la aceleración imparable, lo realizan las incursiones de Marco Ospina en la abstracción. Las obras de este artista son un signo claro de aceleración en la modernidad plástica en tanto revelan la tensión y análisis de una producción que se ubica entre la figuración y la abstracción y que se mantendrían desde la aparición de Capricho Vegetal en 1942.

A partir de este punto, la temporalidad del arte moderno no sólo se enruta nuevamente en otra dirección sino que acelera significativamente sus dinámicas. El medio por el cual se genera ahora este cambio es un plegamiento del arte sobre sí mismo: la producción artística que ha de consolidar su espacio extraterritorial acelera sus dinámicas tomando como objeto la obra de arte misma, sus valores y desarrollos, su lenguaje formal y la síntesis simbólica de sus contenidos, su crítica profesional e instituciones de legitimación social, es decir, la obra de arte moderna deviene un miembro pleno del mundo del arte. Para 1948, la agitación política fue de la mano de la revolución artística: en este año ocurre una explosión de actividades como el inicio de las críticas de arte de Casimiro Eiger en la Radiodifusora Nacional; también Alejandro Obregón reemplaza en la dirección de la Escuela de Bellas Artes de Bogotá a Miguel Díaz Vargas, participa con sus contemporáneos en el Salón de Jóvenes Artistas y organiza el Salón de los xxvi; y Marco Ospina revela una producción de trabajos abstractos y semicubistas. La aceleración continuaría durante los años cincuenta con los aportes que los nuevos artistas harían de continuos viajes a Europa y Estados Unidos - motivados por los problemas de orden público- y con la consolidación de una crítica profesional abierta al público general. Con estas variables en vigor y en plena consolidación de sus relaciones, el arte moderno colombiano adquiere un sentido arraigado en la sociedad colombiana que hace que entre 1954 y 1960 se acelere la transformación del arte colombiano en un arte insertado en la modernidad, esto es, plenamente consciente de sus posibilidades como producción estética. Así, pues, frente a la inercia heredada del siglo xix, el acontecimiento del arte moderno en Colombia responde, a partir de la década de 1930, con un proceso de cambio y aceleración que incide en la complejización de las variables de conformación del mundo del arte colombiano de mitad de siglo xx — formación de sentido que habría de estabilizarse y normalizarse en los años sesenta como producción artística dominante.

Apéndice 3: En términos semióticos, el concepto de acontecimiento puede ser descrito como una transformación de las propiedades del signo en virtud de la estabilidad de una cadena significante. Al considerar el signo de manera aislada encontramos que, respecto a la instauración del componente significante, el signo es arbitrario, y respecto a la eficacia del significado, está supeditado a la transitoriedad que le imprime el contexto de la enunciación. Las interrelaciones y prioridades de estas propiedades varían de acuerdo al bagaje de contenidos simbólicos y a la pericia en el manejo contextual de los signos por parte del interpretante. Sin embargo, cuando se consideran los signos desde el significante se hace notorio que entran en cadenas y acoplamientos en los cuales un signo es materia significante de otro. La formación de esta red significante varía estableciendo diversos regímenes de signos que, en virtud de su complejidad y estructuración, inaugura una frontera estable entre una red significante y una red de significado. Así, esta doble estructura concreta ahora las cadenas de explicaciones que antes dependían de la capacidad del interpretante para pasar a convertirse en un esquema que atraviesa y reproduce la sociabilidad de los miembros de la red - el interpretante se hace parte de la misma estructura. Con ello, el esquema adquiere estabilidad dinámica en su composición y desarrollo espacio-temporal y reproducibilidad contextual que rechazan su antigua 
arbitrariedad y transitoriedad. El Acontecimiento es un esquema sígnico en el cual se entrelazan contenidos simbólicos, referentes prácticos y condiciones espaciotemporales que producen y aseguran la fiabilidad - y posible repetición - del sentido general. El Acontecimiento, visto desde esta perspectiva, es la consolidación del sentido de un esquema sígnico gracias a la modificación de las propiedades del signo: se hace extensible en red, estable y reproducible.

\section{DEL DISCURSO}

Todos los cambios, procesos, espacios, tiempos, todas las múltiples relaciones que problematizan la emergencia del acontecimiento arte moderno en Colombia atraviesan un doble plano: el plano de la multiplicidad de relaciones que conforman estados de cosas y los efectos de significación que ellos comportan y actualizan. El acontecimiento arte moderno en Colombia ocurre, en principio, en la intersección de las distintas series problemáticas que hasta aquí hemos presentado; en su mutuo entrecruzamiento nace el sentido del Acontecimiento, esto es, la posibilidad de hablar de un tipo particular de producción artística en un espacio y tiempo singular de configuración, un mundo del arte. La posibilidad de hablar del arte es, entonces, el último componente problemático de este Acontecimiento, el cual se revela en los efectos de sentido que generaron los discursos y concepciones acerca del arte. Así, esta serie problemática del acontecimiento es aquella en la que se unifica el lenguaje sobre el mismo para estabilizar el sentido de la expresión - con todas sus condiciones materiales efectuadas en el mundo de relaciones institucionales-arte moderno en Colombia.

¿Puede decirse o no, desde el punto de vista actual, que una obra como Montañas de Débora Arango (1940) es una obra de arte moderno? Hoy en día, nuestra respuesta afirmativa sería rápida e irrebatible. Pero esto, precisamente, es un efecto de sentido de unos procesos y modificaciones en el discurso que alteraron el panorama de difusión así como las categorías de referencia al arte. Entre la década de los años treinta y parte de los cuarenta, no había aún en Colombia un lenguaje consolidado desde la estética y la crítica para referirse a una obra como esta. De hecho, la voz hegemónica fue la del repudio y la negación de la artista, la presentación del desnudo Montañas en el I Salón fue motivo de fuertes críticas, en su mayoría ad hominem o de índole política (Lleras, 79). No fue la primera vez que la prensa se refería a la obra de Arango desde un punto de vista moralista o politizado: ya en su ciudad natal, tras la Exposición del Club Unión en 1937 en la cual ganó el primer premio, pintores profesionales y comentaristas de prensa escandalizaron y rechazaron la irreverencia de sus desnudos (Londoño, 78). Pero el efecto más relevante de esta formación discursiva en torno a la obra de Arango durante el periodo no es la polémica que la obra suscita - lo normal es que suscite polémica y que ésta pueda hacer parte de la consagración del artista-, sino el de la separación y aislamiento de la obra de Arango: luego de su participación en el I Salón, tras recibir las diatribas de las clases dirigentes, la obra de Arango es silenciada y su presencia es expulsada del mundo del arte. Sus obras no tienen acogida comercial y la artista se margina de participar en grandes exposiciones hasta que deja el país en 1946. Este silencio no es sólo práctico; es también histórico pues en la narración de la historia del arte en el periodo es notoria la ausencia 
de la artista, «cuyo nombre se ha reivindicado a medias apenas en los últimos años de su vida, cuando su obra coincide con una de las tendencias más vigentes en la pintura figurativa del final del siglo» (Gil Tovar, 331). La marginación efectual al nivel de las prácticas y procesos del arte conllevó un silenciamiento discursivo que excluyó a la artista hasta que fue renovado el lenguaje teórico del arte moderno.

Este caso ilustra la necesidad de que el discurso del arte en Colombia fuera renovado y desarraigado del debate político que determinaba el clima cultural del país (Medina, $E l$ arte colombiano de los años veinte y treinta, 281). En la década de los treinta, liberales así como conservadores, manifestaron su rechazo a las producciones artísticas modernas que, a sus ojos, no podían cumplir función social alguna o que, para algunos, significaban expresiones de inmoralidad y decadencia. Paradójicamente, fue durante los gobiernos de Mariano Ospina y Laureano Gómez que el discurso del arte halló su medio de renovación y transformación: ya no era un discurso que llevaba la obra al centro del debate ideológico sino un vocabulario centrado en la plástica y en sus posibilidades y limitantes, es decir, se consolidó en estos años una crítica profesional del arte. Sin embargo, caso similar al del territorio de la producción, la consolidación de una crítica centrada en la obra tuvo como referentes un conjunto de teóricos y críticos extranjeros que laboraron en el país: el austriaco Walter Engel, el polaco Casimiro Eiger en la radio, el español Clemente Airó en la dirección de la Revista Espiral, el intelectual alemán Juan Friede, el español Francisco Gil Tovar, el uruguayo Arístides Menenghetti y la argentina Marta Traba fueron los encargados de renovar el discurso del arte colombiano asumiendo criterios definidos y con un compromiso público en sus palabras por las nuevas propuestas artísticas. Fue un grupo formado en las vanguardias europeas y con un lenguaje capaz de reconocer la producción emergente en términos estéticos y designarla frente a la sociedad colombiana como el arte moderno del país (Jaramillo, Una mirada a los orígenes del campo de la critica de arte en Colombia, 21).

Este grupo hace del Salón Nacional un espacio cosmopolita de discusión y reflexión del arte. Discurso y práctica logran en la década del cincuenta incidir en la unificación de un vocabulario propio de la plástica colombiana que se reflejará en su mutua consolidación como arte moderno. Así, el grupo de extranjeros — al que habría que sumar a Vidales y Gaitán Durán-, cambian el punto de referencia del discurso al poner como objeto de análisis la obra de arte misma y con ello generar nuevas pautas de reflexión plástica, que le abren campo a la generación de relevo (Jaramillo, Una mirada a los orígenes del campo de la crítica de arte en Colombia, 34). El enunciado rector del arte moderno colombiano excluye a partir de los años cincuenta los compromisos ideológicos que daban resonancia a la polémica política y, por el contrario, forma un incentivo a la internacionalización del arte colombiano que es ahora consciente de sus valores plásticos, de su comprensión de los lenguajes modernos del arte y de los aportes que puede hacer al mismo desde su posición y que definen los rasgos de su producción.

El problema central aquí que caracteriza la univocidad del acontecimiento arte moderno en Colombia es que el discurso sobre el arte revela un nuevo pliegue en el que el arte, o el mundo del arte, reflexiona sobre el arte mismo sin otros criterios que la singularidad de la producción artística del país, la necesidad y apoyo de sus prácticas disciplinares e institucionales. Así, la autorreferencialidad y coherencia del discurso, en particular de una crítica profesional de arte que responde a una producción con un dominio propio y autónomo, instituyen los parámetros con los que hoy identificamos el arte moderno en 
Colombia, pues el discurso autorreferente, plegado en la obra, deviene una «actividad independiente y apoyada en sus propios lineamientos conceptuales, una indagación que contempla la definición de sus objetos de conocimiento, sus metodologías y propósitos más específicos» (Giraldo, 26). Consolidada así la univocidad del sentido del arte moderno en Colombia, y en virtud de este conjunto de vocabulario y referentes institucionales para los cuales la obra es el punto atractor, el arte asume a una voz la emergencia, sentido y realidad de una nueva producción que transformó la historia del arte en el país.

Con este breve y general recorrido, he querido hacer notar cómo la intervención de cada serie problemática, que en sí misma amerita un examen riguroso, queda cubierta con la unificación de un sentido para el cual la multiplicidad de eventos y transformaciones espacio-temporales son su materia de expresión y dan cuenta, una vez efectuado como acontecimiento, de la relevancia y consolidación de la formación de una expresión plástica única en el país que hoy identificamos como el ‘arte moderno colombiano».

\section{REFERENCIAS}

Barney-Cabrera, Eugenio. Geografía del arte en Colombia. Cali: Universidad del Valle, 2006. Medio impreso.

Danto, Arthur. «The Artworld». Journal of Philosophy 19, vol. 61. (1964). 571-584. Medio impreso.

Deleuze, Gilles. Lógica del sentido. Barcelona: Paidós, 2005. Medio impreso.

Eiger, Casimiro. «El propósito loable de fomentar las artes y un creador polémico». $\mathrm{Ca}$ simiro Eiger. Crónicas de arte colombiano. Bogotá: Banco de la República, 1995. Medio impreso.

Gil Tovar, Francisco. Colombia en las Artes. Bogotá: Imprenta Nacional, 1997. Medio impreso.

Giraldo, Efrén. La crítica del arte moderno en Colombia, un proyecto formativo. Medellín: La Carreta, 2007. Medio impreso.

González, Beatriz. «El termómetro infalible». Colcultura, Salón nacional de artistas XXXIII: 50 aniversario 1940-1990. Bogotá: Colcultura, 1990. Medio impreso.

Jaramillo, Carmen María, «Una mirada a los orígenes del campo de la crítica de arte en Colombia». Artes La Revista 7. vol. 4 (2004). 3 - 38. Medio impreso.

. «Una aproximación a la consolidación del arte moderno en Colombia». Textos 13 (2005). 7-68. Medio impreso.

Lleras, Cristina. «Politización de la mirada estética: Colombia, 1940-1952». Textos 13 (2005). 99-112. Medio impreso.

Londoño, Santiago. Débora Arango: vida de pintora. Bogotá: Ministerio de Cultura, 1997. Medio impreso.

Medina, Álvaro. Procesos del arte en Colombia. Bogotá: Instituto Colombiano de Cultura, 1978. Medio impreso.

. El arte colombiano de los años veinte y treinta. Bogotá: Colcultura, 1995. Medio impreso.

Quinche, Víctor. «Andrés de Santamaría y la identidad del arte colombiano». Reporte 45. Bogotá: Universidad del Rosario, 2003. Medio impreso. 
Rubiano, Germán. «Pintores y escultores «Bachués»». Historia del arte colombiano, Bogotá, Salvat, 1976.

. «El primer arte abstracto en Colombia». Historia del arte colombiano. Bogotá: Salvat, 1976.

. «Museos, Salones, Bienales, Escuelas». Historia del arte colombiano. Bogotá: Salvat, 1976.

Recepción: Septiembre 2011

Aceptación: Marzo 2012 